\title{
Fundamentación de las ciencias espirituales
}

La fundamentación de las ciencias espirituales, no sólo obedece a la necesidad de captar sus más profundas y sustantivas razones, sino también a la de conferirle el rango de objetividad, más que en chlalguier otro sector del conocimiento, indispensable en estas ciencias. Fuera de la tentativa metafísica de Hegel, los esfucrzos más significativos y recientes en este sentido se refacionan con los nombres de Enrique Rickert, Guillermo Diluhey y Eduardo Spranger.

Teoría de Rickert.-Vinculaclo al neo-criticismo en la forma adoptada por lat escuclit sud-roccidental alemana, Rickert afrontar of probilenla Glengerfundamentación de las ciencias espirituales, tratando de esclarecer, principalmente, el tipo de conocimiento que les corresponde.

En breve expresión esquemática, la filosofía de Rickert reduce el mundo a tres instancias: I) la realidad: 2) el valor, enticlad puramente icleal; 3) la vivencia del sentido, o sea el conjunto de los actos comprensivos del valor. La simple enunciación de estas cuestiones nos advierte que Rickert no es un idealista subjetivista; en efecto, el idealismo de Rickert, al admitir la existencia de una realidad, se debe considerar como trascendental. El problema de la trascendencia es, para él, problema fundamental de la teoría del co- 
nocimiento. Pero esta realidad no es la del realismo ingenuo, sino aquello que puede designarse con la expresión kantiana "conciencia en general" (Bewusstsein z̈berhaupt), esto es, tuna conciencia impersonal, general, innominada, lo único que nunca prede convertirse en objeto o conteniclo de la conciencia. Esta concepción no niega la existencia del mundo espacio temporal que nos rodea, pero sostiene que todo ser es un ser en la conciencia.

La noción de valor desempeña en la teoría general del conocimiento cle Rickert un papel muy principal. Conocer es, según él, juzgar, es decir, un afirmar o negar, un aprobar o desaprobar, un tomar posición frente a un valor. Tal afirmación o negación no se funda en impulsos psicológicos, sino mas bien en un deber, en algo que se nos opone desde fuera. Un juicio es correcto, porque juzga como debe ser juzgado, no porque dice lo que es real. Nuestros juicios no son rerdaderos porque enuncian lo real; llamamos real a lo que debe ser reconocido como real por nuestros juicios. De esta manera, Rickert formula un concepto axiológico de la realidad.

Rickert distingtre claramente el cebee del valor. Valor es lo que vale (aunque no existe) en sí De por, sí. El valor se funda en sí mismo; el deber, en cambio, está relacionado con un sujeto, a quien le exige obediencia. Los valores no tienen otro modo de ser que el del valer (Gelten) y forman un reino, que se encuentra más allá del sujeto y del objeto.

También distingue Rickert el valor de las valoraciones, que son actos de aprehensión de los valores. En este tipo de actos, el sujeto toma posición con relación al valor absoluto. Huelga decir que el valor no puede entenderse como hecho psíquico, sino precisamente como un "pasar sobre" lo psíquico, en dirección a los valores. $\mathrm{Ni}$ es tampoco un valor, sino un simple apuntar a valores. El ser del valorar es lo que Rickert llama su sentido (Sinn). En esta forma se constitu- 
ye el reino del sentido, intermedio entre el reino del valor y la realidad y cuya misión es unir a ambos.

Señalada la importancia que Rickert atribuye a los valores en su filosofia en general y en su teoria del conocimiento en particular, pasamos a exponer sus ideas sobre el tema "Ciencia cultural y ciencia natural", materia de un libro muy conocido entre nosotros por la respectiva versión española.

Rickert distingtue las ciencias culturales de las naturales; pero considera que no se refieren realmente a materias distintas, mejor dicho, que no se distinguen por sus objetos. Según la distinción entre las ciencias culturales y maturales se funda propiamente en la lógica, en la manera de elaborar sus conceptos, pero no en la gnoseologia, ni mucho menos en la ontologia propiamente dicha. Los métodos y procedimientos para la captación de sus objetos son radicalmente distintos; pero sus objetos mismos no lo son. (I)

Esta pura diferencia lógica entre las cjencias culturales y las naturales, reside en la forma de su conceptuación. La realidad, en su fondo, es irracional, pero nosotros tendemos sobre ella una red racional de intelección, y procedemos según sea el punto de vista natural, o cultural, de dos maneras completamente distintas. Desde el punto de vista natural, utilizamos la conceptuación generalizadora. Sin parar mientes en las diferencias, dirigimos nuestra atención exclusivamente hacia lo constante. Entonces, con unos cuantos elementos, formulamos un concepto generalizador.

Tal forma de conceptuación es, ciertamente, legítima; pero debe reconocerse que sólo se dirige a la captación de ciertos aspectos de la realidad. Por este medio, toda la realidad puede ser reducida a conceptos generalizadores, tarea a la que se consagra con ahinco (no siempre justificado) (1) Gieneia eultural y eiencia natural, H. Rickert, Espasa-Calpe. Trad. de
Manuel G. Morante. 
la ciencia natural. Desde luego, este problema no podia planteárselo quien, como Rickert, parte de la tesis inadmisible desde todo punto de vista, de que las ciencias naturales no difieren ontológicamente de las culturales; y que la única diferencia entre ellas es la forma especial de su conceptuación.

Las ciencias culturales no se interesan en lo universal; se dirigen exclusivamente hacia lo individual. "A quien quiera reservar el nombre de ciencia-dice Rickert-para los productos de la concepción generalizadora no hay, na'turalmente, objeción alguna que oponerle, porque semejantes determinaciones terminológicas caen más allá de la verdad y la falsedad. Pero nadie podrá sostener que sea particularmente feliz y acertada una terminología que no admite el nombre de ciencia para las obras de Ranke y otros grandes historiadores. Mejor fuera, en cambio, esforzarse por elaborar un concepto de la ciencia que comprenda todo lo que generalmente se llama ciencia, y para tal fin sería preciso ante todo tener en cuenta el hecho de que las ciencias no presentan siempre la misna forma depmétodo natura'lista, o sea generalizador'.uDe este modo, reivindica Rickert el derecho de las ciencias culturales o históricas a exigir igual forma de acatamiento que el que merece las ciencias de la naturaleza. Con excepcional claridad, define el carácter individualizador e histórico de las ciencias de la cultura. El que habla de historia-dice-refiérese siempre al transcurso individual y único en el tiempo de una cosa; precisamente en la filosofía es corriente contraponer lo históririco, como particular, a la natural, como universal. El derecho histórico es el derecho singular, el derecho individualmente considerado, en oposición al derecho natural, que es común a todos o que debe ser común a todos. La religión histórica es la religión singular, la religión particular, en opo- 
sición a la religión natural, la cual se cree que está dada a todo hombre juntamente con su naturaleza general humana. (2),

Ahora bien, cómo es que las ciencias culturales se dirigen hacia lo individual. Esta pregunta no se puede contestar si no se hace un análisis de los elementos que constituyen lo individual. En el dominio de lo individual encontramos elementos reales y elementos ideales. Los elementos reales son los hechos. El investigador d.e las ciencias culturales se propone, en efecto, indagar estos hechos. El Renacimiento, la Revolución Francesa, la Guerra Mundial, son hechos de esta especie, y consituyen la materia inmediata y directa que se presenta en el campo de las ciencias culturales.

No bastan, ciertamente, los hechos para la constitución del concepto individualizador científico cultural. Es necesaria, además, la concurrencia de ios valores y la respectiva valoración o captación del valor. La concepción de Rickert respecto a los valores está de acuerdo, en principio, con la de todos los modernos axiologistas, en cuanto considera los valores como meras idealidades. Para Rickert, la conceptuación histórico-individual se rige por valores. Si los procesos culturales se distinguen de la naturaleza, esto se debe únicamente al punto de vista de los valores, es decir, al procedimiento avalorativo, característico del método individualizador-histórico, opuesto al procedimiento de la ciencia natural, dirigida al descubrimieno de conceptos universales que, en la forma de conexiones legales, establecen un enlace de constancia entre todos los hechos del mismo tipo, sin ocuparse para nada de la referencia a los valores culturales. Tal referencia a los valores se advierte claramente en la labor del historiador, quien trata sólo de exponer lo signifi-

(2) Ciencia Cultural y Ciencia Natural, pág. 74. 
cativo, lo importante, lo interesante, lo esencial, sin cuidarse de lo que no reune estas condiciones. Es evidente, que los hechos que merecen estos calificativos son hechos valiosos y que no pueden comprenderse sin referirlos a valores. La falta de esta referencia convertiría los hechos expuestos en aburridos, insignificantes y triviales. Al perder el relieve que les otorga la referencia al valor, perderían también su importancia histórica, rebajándose y confundiéndose en el mismo plano de los hechos comunes, donde los destacó la avaloración del historiador.

La selección que el criterio avalorativo introduce en el conjunto de los hechos, se realiza también en el complejo de la misma experiencia histórico-cultural. En la vida de un personaje hay aspectos que son interesantes para. el historiador y otros que no lo son. Los interesantes son los que están dotados de sentido histórico; lo cual se debe, sin duda, a que se encuentran enlazados con valores. Admitido este principio, debe concluirse rechazando de la categoría de ciencia histórico-cultural la labor paciente de los eruditos, quienes pierden su tiempo exponiendo infinidad detetalles sin importancia, cuyo descubrimientoinolafecta en nada el sentido profunclo y esencial de los hechos históricos. Multitud de hechos vulgares, que se toman en consic'eración exclusivamente porque se refieren a determinado personaje histórico son el tema frecuente de sesuclos trabajos de historiografía, sin que aliente en ellos ni la sombra de interés histórico, pues no se refieren a ningún valor cultural ni presuponen en el sujeto ningún talento especial para realizarlos, toda vez que hubieran podido serlo por otro cualquiera y en cual-. quier tiempo.

La concepción de Rickert, y en particular en cuanto se refiere a las ciencias culturales, tiene el acierto de haber puesto sobre el tapete la cuestión de los valores. Los valores 
son efectivamente lo que da scntido a los hechos humanos, el significado permanente de cualquier suceso histórico. Además, los valores constituyen el factor objetivo en el conocimiento histórico. En efecto, un concepto, referico únicamente a hechos, sólo sería capaz de reproducir, manteniendo todos los contenidos históricos en el mismo plano. I.o que permite, en cambio, destacar y car relieve, individualizando los contenidos históricos, son los valores. Gracias a la captación de los valores, el conocimiento histórico se puede apoyar en bases firmes, captanclo la realidad objetiva de los hechos, y apreciándola con un criterio igualmente objetivo, superior a la simple opinión personal y al punto de vista relativo en que nos encontramos colocados. En otros términos, el valor es lo que hace posible que la historia sea ciencia y que se pueda hablar con derecho de ciencias culturales particulares.

Es muy discutible la limitación metódica en que se encierra Rickert. Nadie puede negar hoy que entre la ciencia cultural y la natural hay una diferencia metódica, lógica; pero afirmar que esta es la única, que no existe una subyacente diferencia ontológica, es inadmisible. Justamente, esa diferencia es la que permite la diferenciación de los métodos. La evidencia de que la exposición del desenvolvimiento del huevo, hecha por von Baer, para usar un ejemplo tomado del mismo Rickert, es algo completamente distinto de la historia que hizo Ranke de los Papas romanos en los siglos XVI y XVII es el fundamento de la distinción metódica entre ciencia natural y cultural; y por otra parte, a nadie se le puede ocurrir, aunque aquí se emplea el concepto de desarrollo, identificar un proceso natural evolutivo, como en el que presenta von Baer, con la verdadera historia de la cultura, como caso presentado por Ranke. El mismo Rickert, en el capítulo correspondiente de Ciencia cultural y Cien- 
cia natural, reconoce que aquí hay una "diversidad de problemas", y que de ella se sigue que deben existir diversas formas lógicas de tratarlos. Lo único que queda por dilucidar es, si todos los problemas de las ciencias culturales pueden ser tratados en forma lógica, conceptual, o si se requiere ejercitar alguna facultad especial más en armonía con los objetos de la investigación cultural, asunto que se puede tratar mejor al exponer, en seguida, las ideas de otro gran teórico de las ciencias espirituales: Guillermo Dilthey.

Teoria de Dilthey.-La actitud de Dilthey frente a las ciencias espirituales es semejante a la de Kant frente a las naturales. Del mismo modo que Kant fué el gran pensador crítico de las ciencias de la naturaleza, Dilthey lo fué de las ciencias del espíritu. Así como Kant intentó fundar una teoría del conocimiento natural, Dilthey se propuso construir una teoría del conociniento espiritual.

El punto de partida de este pensador es una nueva concepción de la psicología. Hasta la época de Dilthey, la psicología que prevalecía en todos los campos era el asocianismo, que concebía el muindocespiritual y psíquico a semejanza del mundo material. En efecto, asi como el mundo material está constituído por diversos elementos irreductibles que se enlazan en virtud de determinadas leyes, el mundo espiritual está también formado por elementos simples, vinculados entre sí por las leyes de la asociación, de donde viene el nombre de asociacionismo con que se conoce este estilode psicología. Tal imagen del mundo es naturalista y falsa, según Dilthey, porque concibe falsamente lo espiritual a imagen y semejanza de la natraleza de los físicos, trasladando al dominio de la vida anímica la visión atomista y mecánica que prevalece como fundamento de toda noción sobre los hechos naturales y sus relaciones. Además, el asociacionismo es explicativo. 
Por asociación se forma la percepción, la imaginación, el juicio, el raciocinio; por asociación se recuerda, se piensa, constituyen las ideas generales; por asociación surgen los estados afectivos y volitivos; por asociación, por último, se erige la personalidad en centro de nuestra vida psíquica, en el que confluyen recuerdos, imágenes, ideales, todo lo cual a su vez ha tenido su base en infinidad de síntesis de sensaciones. De acjuí procede la teoría de que todo es sintesis, descle las sencillas que se producen en el plano de los hechos elementales, hasta las complejas que dan origen a los fenómenos superiores de la vida anínica. Se considera la vida espiritual como si fuera un simple mosaico, donde los hechos elementales se componen y descomponen como trozos de madera. Contra esta concepción de lo animico reaccionó fuertemente Dilthey, reprochándole su nattiraleza constructiva y atomística, y haciendo resaltar al mismo tiempo su estéril tendencia explicativa, es decir, su propensión a atender a las circunstancias o razones de los hechos más que a los hechos mismos, a reducir la totalidad a sus elementos simples, a atender a lo formal y a do legal, antes que al riquísino contenido de la vida espiritual.

Según Dilthey, la psicologia debe buscar su verdadero centro; debe ser ante todo descriptiva y analítica y no explicativa y de elementos. Debe saberse ante todo cómo es la vicla espiritual; y esta finalidad solo puede cumplirla una psicologia que comprenda la vida espiritual en su totalidad, en su estructura, no en sus elementos. Pues bien, el enfoque del problema descle este punto de vista constituye uno de los más grandes sucesos en la historia de la psicología, tanto por lo que significa en si mismo como por sus repercusiones en todas las direcciones de la cultura.

La noción de estructura,-que es ftundamental para entender la psicología de Dilthey,-puede ser definida des- 
de el punto de vista formal y desde el punto de vista material. Formalmente, estructura es el enlace vivencial mutuo c.e hechos psiquicos diversos. Nuestra experiencia intima nos muestra, en efecto, cómo se enlazan, se apoyan, se refuerzan $y$ se funden en una unidad estructural los elementos ante sólo por el análisis podemos distinguir en la vida psífuica. Naterialmente, en la estructura hay enlace reciproco de la aprehensión de lo real, del sentimiento de los valores y de la realización de fines vitales. El sentido material de la conexión estructural muestra el carácter concreto del análisis de Dilthey, su instalación en la vicla psiquica real, tal como se presenta en la dimensión histórica.

A la noción de estructura, ingrega Dilthey la determinación de dos caracteres propios det complejo anímico: evo lución e historiciclad. Estos caracteres precisan los contornos del complejo y permiten su adecuada comprensión. Transformarse, cambiar constantemente es rasgo que se advierte en la vida psíçuica con evidencia immediata. Tal transformación se opera gracias a la naturaleza teleológica de lo anímico, según da cuabes el todo lo ques determina los elementos, y no a la inyersa. Pero, como la evolución no es un simple pasar sin de jar huella, sino que, al contrario, implica acumtlación, la imagen de lo psíquico se nos presenta en todo momento con la plenitud de su valor, como totalicad coordinada internanjente con los momentos precedentes y cnlazándose en conexiones cada vez más amplias, a través de todas las edades de la vida, es decir, en la forma de una verdadera historia.

Previa esta sumaria aproximación a la psicología de Dilthey, nos queda por hacer ver la forma en que esta nueva concepción cle lo espiritual contribuye a la fundamentación de las ciencias espirituales, es decir, cómo, en el pensamiento de Dilthey, se puede pasar del plano psicológico y 


\section{$-74-$}

subjetivo al histórico cultural. En realidad, lo que Dilthey llama vivencia se encuentra mucho más acá de las distinciones entre lo objetivo y lo subjetivo, porque vivencia es lo vivido real o mejor dicho lo realmente vivido por el individuo. En este vivir, se nos dan objetos, vivimos un mundo que está frente a nosotros; por lo tanto, la vivencia no es una experiencia subjetiva, interior, abstracta, sino un auténtico vivir, un vivir algo en si mismo, no un puro discurrir solipsista. De esta suerte, en la vivencia se encuentra la clave y la garantía de la interpretación o hermenéutica.

En todas las formas de la vivencia, se observa una transición de lo interno a lo externo, que constituye la expresión. Esta transición no es absoluta, porque siempre queda en la vivencia algo irracional, que no alcanza a asumir la forma de una expresión permanente. Las expresiones son de tres clases: teoréticas, comprendiendo los conceptos, los juicios, los raciocinios, y en general todas las formas del saber científico; expresiones de la sabiduri de la vida, del arte, de la religión, de la filosofía; y expresiones prácticas, relacionadas con laoconducta del individuo, es decir, con la posición de fines.

Por la "expresion nos instalamoso"

llam expresion nos instalamos en el reino de lo que llama Dilthey, siguiendo la inspiración de Hegel, el espiritu objetivo, que es objeto de las ciencias espirituales.

Aquí es necesario desprendernos de la psicología, y acudir a otra ciencia, la hermenéutica, cuyo dominio es el reino de las expresiones, y cuyo objeto es interpretarlas cientificamente. En el fondo, pues, el problema de la hermenéutica es la comprensión (Verstehen).

Los problemas de la hermenéutica se pueden reducir a tres: I) contemplar la posibilidad de aprehender algo relativamente extraño a nosotros. En efecto, "la interpretación sería imposible, si las expresiones de la vida fueran total- 
mente extrañas; y sería innecesaria, si en ellas no hubiera nada extraño". (3)

2) debe dar reglas para la interpretación. La genialidad del investigador es, realmente, to que concuce con acierto en la tarea de interpretar las expresiones; pero su manera de actuar se convierte en una técnica y se desarrolla con el desenvolvimiento de la conciencia histórica. De esta suerte, la comprensión se vuelve más segura y se aprovechan las experiencias ajenas. Además, al lado del aspecto positivo, al que no debe darse mucha importancia, se debe valorizar el aspecto negativo de la regulación, representado por la critica, la cual "nace de las dificultades que presenta la interpretación, y conduce a la limpieza de los textos, a la descalificación de documentos, obras, tradiciones." (4)

3) Por último, la hermenéutica debe asumir la importantisima tarea de determinar las condiciones para obtener conocimientos universalmente válidos. Si el conocimiento histórico clebe permanecer encerrado en los límites de lo individual, tenemos que renunciar definitivamente a la constitución de una ciencial historica; pues lo que pernite que el conocimiento de estéorden alcance la dignidad cientifica no es otra cosa que su validez universal. Desde luego, en el campo en que se sitúa Dilthey, es muy dificil resolver este problema; y sin embargo, se tiene que plantear. En efecto, determinar categorias para el conociniento racional, en el sentido de Kant, es comprensible y factible. Pero Dilthey pretende realizar este propósito en el dominio de la vida espiritual, considerada en su totalidad, lo que equivale a alcanzar fines que son propios de la razón en el dominio de lo irracional y con medios irracionales, toda vez que

(3) Dilthey, Gesammelte Sehriften, 7 pág. 225.

(4) Ibid. púg. 217. 
la comprensión exige lá colaboración de "todas" las fuerzas del ánimo, no exclusivamente de las intelectuales.

Las categorias del conocimiento espiritual objetivo señaladas por Dilthey, se clividen en formales $y$ materiales. Las primeras surgen de las formas clementales del pensamiento y son atributos de toda lá realidad. Ellas con: unidad, multiplicidacl, igualdad, diferencia, diferencia de grado, relacion. (5) "Las categorias formales son expresiones abstractas para lás modaliclades lógicas del distinguir, iclentiticar, concebir los grados de la diferencia, vincular, separar. Constituyen, por decirlo así, una aprehensión de más alto grado, que solamente constata, pero que no construye a priori. Se presentan ya en nuestro pensamiento primario y ituego se hacen valer en nucstropensaniento discursivo, en un grado más elevado. Estas categorias son las condiciones formales tanto del comprender (Verstehen) como del conocer (Erkennen), de las ciencias espirituales como de las naturales." (6)

Las categorías materiales se refieren a los contenidos mismos; por fo tanto ne pueden aspirab al mismo graclo de seneralidad que las formales: Dillheys no establece una clasificación completa de estas categorías, pero consigna las de realidarl, cosa, causalidad, valor, fin, medio, significación, cesarrollo, formación, sentido, etc. (7) Naturalmente, en las ciencias espirituales no rigen las mismas categorías que en las naturales, por lo menos en cuanto a su forma de validez. La transposición alustracta de las categorias naturales al dominio de las ciencias clel espíritu da origen a una verdadera transgresión, tan inaceptable como la contraria, es decir, la que consiste en aplicar las categorías espirituales al

(5) Tluíl. pág. 196.

(6) Ibid. prg. 197.

(i) Ibid. pag. 302 . 


\section{$-77-$}

campo de las ciencias naturales (Filosofia Natural de Schelling y (le Hegel). Así, por ejemplo, no existe causaliclad natural en el munclo histórico, no hay causas que produzcat efectos necesariamente y de acuerdo con una ley. En la historia, dice Dilthey, sólo hay acción y pasión, acción y reacción. Auncule formalmente se apliquen algunas categorías, tanto al mundo histórico como al mundo natural, su significación es distinta cu anbos casos; aś la categoría formal de la relación del todo a la parte, empleada también en la ciencia natural, recibe un sentido propio en el campo de las ciencias espirituales, que procede de la esencia de la vida y que tiene su realización o cumplimiento no sólo en la vida orgánica, grado intermedio entre to inorgánico $\mathrm{y}$ el mundo espiritual, sino también en forma estrictamente individual, en la formación de los seres espirituales singulares. Por ilustración, trascribimos algunos fragmentos de Dilthey, relacionados con la determinación de categorías individuales en el estudio de autobiografías, "las formas suprennas y más instructivas en las que se nos presenta la comprensión (Verstehen) de la vida".

Agustín, Rousseat, Goethe nutuestrathasus típicas fornuas históricas. ¿Cóno eaptaniestoś escritores la conexión de su propio transcurso vital? Agustín está dirigido completamente al enlace de su existencia con Dios. Su obra es al mismo tiempo meditación religiosa, plegaria y narración. Esta narración tiene su meta en el suceso de su conversión y todo acontecimiento anterior es sólo una estación en el camino a esta meta, en la que se decide la intención de la Providencia con este hombre. Ningún goce sensible, ningún entrusiasmo filosófico, ninguna alegría de retórico por el brillo del discurso y ninguna otra relación vital tiene para él $u_{n}$ valor en si. En todo, siente el contenido vital positivo raramente mezclaco con el anhelo de aquella relación trascendente; todo es pasajero y recién en la conversión nace una relación eterna y feliz. Así, comprende su vicla en la relación de las partes 
de la misma a la realización de un valor absoluto, de un bien supremo incondicionado, y en esta relación mira retrospectivamente la significación de todo momento vital anterior. No encuentra en su vida desenvolvimicnto, sino preparación para la desviación de todos los pasajeros conteniclos cle la misma hacia su fin,-Rousseau. En las Confesiones, la relación at su vida puede ser captada solamente en las mismats categorías de significación, valor, sentido, fin. Toda Francia estaba llena de murmuraciones solre su matrimonio, sut pasado. En horrible soledad contemplaba la acción incesante de sus enemigos contra él, misántropo hasta el delirio de persecución. Si atendía a sus recuerdos, se veia educado en el estricto orden calvinista de la casa; luego, surgiendo difícilmente de tuna obscura vida de aventurero a la actividad del grande que vivia en él, enlodado en su camino por todo el tango de la calle, mal alimentado, impotente frente al dominio cel mundo distinguido y de los espíritus selectos a su alrededor. Pero, de todos modos, apesar de lo gue hubiera hecho y sufrido y de ta corrupción que hubiera en él, se sintió como una alma distinguida, generosa, con sentimientos de humanidad, en lo que consistía el ideal de su tiempo. Eso era lo que él quería poner al mundo ante los otros: quería dar vaior al derechó de sut existencia espiritual, mostráncola tan completa como era. También aquí se interpreta el curso de los sucesos de una vida. Se busca una conexión que no existe en ia mera relación de causas y efectos. Si se quiere expresarla, hay que hacerlo con palabras, como valor, fin, sentido, significación. Si miramos más de cerca, hay una relaciór característica y jerárquica de estas categorias, en la cual se realiza la interpretación. Rousseau quiere ante todo que se reconozca el derecho de su propia existencia individual. En esta se contiene una nueva visión de infinitas posibilidades de realización de los valores de la vida. Partiendo de esta visión se forma la relación de las categorías bajo las cuales es comprendida su vida.-Goethe. En Poesía y Verdad se manifiesta como un hombre universal histórico, con relación a su propia existencia. Se le ve en relación con el movimiento literario de su época. Tiene el tranquilo y orgulloso senti- 


\section{$-79-$}

miento de su posición en ella. Asi, para el anciano, que mira retrospectivamente, es signiricativo todo momento de su existencia en doble sentido: como plenitud de vida gozada y como fuerza que actúa en la conexión cle la vica. Toda presencia en Leipzig, en Strassburgo, en Frankfurt es sentida por él como colmada y determinada por el pasado y como extendiéndose para lá formación del futuro, es decir, como desenvolvimiento. Aquí podenios calar más hondanente en las relaciones que existen entre las categorías de captación de la vida. İl sentido de la vida se encuentra en la formación (Gestaltung), en el desenvolvimiento; desde aqui, se. determina la significación de los momentos de la vida de tma manera propia; ella es af mismo tiempo valor del momento vivido y su fuerza eficiente.

Toda vida tiene un sentido propio, en el cual toda prescncia que se recuerda tiene u nvalor propio; y sin embargo, al mismo tiempo tiene en la conexión del recuer do relación a un sentido del toclo. Este sentido de la existencia individual es completamente singttar, insoluble al conocimiento (Erkennen) y sin embargo representa, como una mónada de Leibniz, el universo histórico. (S)

La teoria de la comprensión histórica reposa, ciertamente, sobre algumos supuestos, tales como la historicidad de la naturaleza humana, la posibilidad de que el individuo se emancipe de la limitación histórica, por el cononcimiento y sobre todo la doctrina ya sostenida por Schleiermacher, segín la ctial entre los seres intelecttuales sólo hay diferencias ctrantitativas, pero no cualitativas. Entre el actor y el intérprete hay una mera diferencia cuantitativa, porque los actos espirituales de que el actor histórico o personaje es capaz, somos capaces nosotros. El tiene representaciones, sentimientos y realiza actos de voluntad. Nosotros nos diferenciamos de él, únicamente, en la fuerza de nuestras representaciones,

(8) Ibid. pág. 198. 
sentimientos y voliciones. Dilthey cree rue todos los procesos psiquicos se desarrollan sobre un fondo estructural comin. Acaso, frente a esta tesis, surge de nuevo el problena si consideramos que no es fo común lo que interesa al objeto del conocimiento histórico, sino precisamente lo que se destaca como singular dentro de lo común, tanto en las conexiones individuales como "en las más amplias conexiones representadas por los succsos históricos. Se adrierte, pues, la necesidad de superar esta limitacion concedienclo al conocimiento histritico los mismos atributos que al conocimiento natural, es decir, reconociéndole aptitud para la captación y elaboración objetiva del mundo cultural : para lo cual, es preciso eliminar la premisa psicologista implicita en la tcoría de la comprension de Dilhey. En efecto, la llamada autognosis (Selbstbesinnumg), conocimiento de si mismo o percatación de si mismo, como propone Ortega y Gasset, no llega a colmar, por más entusiasmo que pongan en ello fervientes expositores de Dilthey, el abismo que meclia entre la "percatación cle si mismo" y la percatación de 10 que no es "sinimismo"tocde locque ya, quor lo menos en parte, ha dejado de ser "si misinol': Alowqueqarece, el conocimicnto histórico, en cuanto comprensión, se nos da realmente en froma mucho más sencilla y directa, rue la que requeriría el rodeo del conocimiento de si mismo. Además, las objetivaciones del espiritu depositadas en el mundo histórico cultural tienen una vida propia, que no puede agotarse en el retroceso interpretativo a los elementos vivenciales. E] mismo Dilthey ofrece en sus interpretaciones historicas ejemplos alucinantes de lo que puede hacer la fuerza interpretativa. en las que la referencia psicológica es un simple aditamento sin importancia de la captación genial.

Teoría de Spranger. - Bajo el fuerte influjo de Dilthey, se desarrolla el pensamiento de Spranger en torno a la teoría 
de las ciencias espirituales y desde luego al método comprensivo. Su punto de partida es también la psicología. Desde luego, rechaza en esta ciencia el atomismo y la tendencia a construir la vida psíquica a base de elementos simples, usual en el asocianismo, cuyo estilo es denominado por Spranger precisamente psicología de elementos. "La psicología de elementos trata de distinguir los procesos de la conciencia individual hasta sus últimos componentes irreductibles." (9)

Frente a esta psicología de elementos, Spranger se decide por una psicología estructural, que comprenda el alma en su totalidad o con relación a totalidades; y la define diciendo, que es toda psicología que comprende los fenómenos psíquicos parciales por la situación que los valores les deparan en el todo unitario y por su significación para estos complejo funcionales totales. (IO) Taj psicología estructural, se funda en el supuesto de que existe un reino de valores, al que se refieren las vivencias de los individuos. EI análisis y la descripción de esas vivencias constituye uno de los capítulos más interesantes de las Formas de Vida de Spranger.

Otra de las nociones fundamentales del pensamiento de Sprenger es lo que llama "sentido". Tiene sentido, según Spranger, lo que es miembro constitutivo de un conjunto valioso. El todo de valor es lo que da sentido a las partes; por consiguiente, las partes no pueden entenclerse por si mismas, sino por relación al todo. El sentido expresa, pues, la relación de algo a un valor. "En una proposición gramatical, tiene cada palabra su sentido determinado, y la proposición entera tiene a su vez su sentido en el complejo de un conociminto o de una declaración, esto es, desde el punto de vista de un valor teorético. $\mathrm{E}_{n}$ una máquina tienen las par-

(9) Eduard Spranger, Lebensformen, pág. 9.

(10) Psicologia de la edad juveni], pág. 28. 
tes un sentico, que está determinado por el trabajo total de la máquina. Una acción tiene sentido cuando es el resultatdo del propósito de realizar un valor y puede comprenderse por un complejo de valores. Los productos y las instituciones de una cultura tienen sentido, cuando contribuyen en algo al todo de la vicla de esa cultura; y pierden su sentido, cuando desaparece esta dependencia respecto del valor del todo". (11).

Ia comprensión de un todo de sentido no siempre se agota en él; a veces un todo de sentido se encuentra incorporado a otro, y éste a su vez a otro u otros. Así se constituye una escala en la comprensión de los todos de sentido, hasta que llegamos a la comprensión absoluta. La estructura de senticlo de un individuro, por ejemplo, puede ser incorporada a la totalidad de su cultural, de su tiempo, a la natura!eza humana, a su posición frente al mundo, etc. A medicla que se recorren estos grados, la comprensión de los todos de senticlo es más adecuacla y más esencial.

Con los conceptos de sentido, estructura y estructura de sentido, eniprende Spranger la tarea de discriminar los tipos humanos fundamentales, lo que supone la captación comprensiva de las diversas direcciones que puede seguir la formación espiritual del indivicluo con relación a la constelación de los valores. Distingue los seis tipos siguientes: teorético, estético, económico, social, político y religioso. El tipo teorético está orientado hacia la objetividad; su ley formativa es la de la verdad. El tipo estético se dirige hacia la formación de valores artísticos; su ley es la de la forma. El hombre económico se orienta hacia fines utilitarios; su ley es la de obtener medios para conseguir sus fines. El tipo social está clirigido hacia los valores de la caridad, la

(11) Psicología de la Edad Juvenil, E. Spranger, pág. 22. 
justicia, el amor; su ley es la del amor. El tipo político se orienta hacia el poder; su forma legal es la voluntad de poder. El tipo ético-religioso se dirige hacia el valor total de la vida; su ley es la sumisión, la devoción, la inclinación a la ley suprema y total de la vida.

La simple descripción de estos tipos nos hace ver claro la conexión que existe entre el orden subjetivo y el objetivo, en otros términos entre el alma individual o espíritu subjetivo $y$ las objetivaciones espirituales, designadas tpor Spranger como espiritu objetivo, siguiendo la tradición de Hegel y Dilthey. En buena cuenta, pues, esta psicología científico-espiritual constituye un elemento interpretativo muy valioso para las ciencias espirituales; puesto que toda ciencia espiritual, para comprender su objeto, tiene que retroceder hasta estas estructuras de sentido fundamentales descritas por. Spranger, las que a su vez, como ya se ha dicho significan algo por su relación con los valores.

La determinación de los tipos de vida espiritual, así como la determinación de las estructuras objetivas culturales a las que estos tipos se refieren, implican una teoría de la comprensión. Spranger distingte expresamente piscología descriptiva de explicativa, la primera fundada solamente en el revivir. La psicología comprensiva necesita además reposar en formas categoriales, en nexos de sentido, que el pensamiento imprime al material empírico de las vivencias intimas. La mera reproducción intuitiva de la serie de los estados internos de otro, no es comprender; como tampoco tener excitaciones retinianas es ya ver, en el sentido de percibir. (12) En efecto, la mera reproducción inplica una limitación, y conduciria al caos, sin un criterio regulativo, sin una elaboración selectiva capaz de adherir a lo

(12) Psicología de la Eład Juvenil, pág. 25. 
esencial, adscribiéndola en totaliclades de sentido cada vez más amplias. Ia comprensión debe tener, pues, un valor gnoseológico, es decir, debe ser mucho más que una simple resonancia interior o un simpatizar. "Comprensión es un acto teorético muy complejo, en el que concebimos, con pretensión de objetividad, la conexión interior plena de sentido, en el ser y en el hacer, en el vivir y en el conducirse de un hombre, de un grupo humano,o en el senticlo de una objetivación espiritual". (I3) No es un mero transportarse dentro de una totalidad espiritual (Sichhineinversetzen); implica la captación de objetiviclades reales, lo cual sólo puede tener lugar en actos teoréticos efectivos. Para que se realice esta transición a la objetiviclad, no es necesario que exista una afinidad personal entre el que comprende y el objeto de la comprensión. En este sentido, no es apropiada la teoría de Dilthey de la homogeneidad cualitativa. Si lo fuera, estaríamos condenados a comprender solamente lo homogéneo, o a comprenclernos solo a nosotros mismos. Precisamente lo contrario parece verdad: comprendemos mejor lo que nos es distinto o ajeno y tenemos gran dificultad para comprendernos a nosotros mismos Los extraños son los que mejor nos comprenden; y más fácil que comprender la situación actual, nos es comprender situaciones y personajes históricos. Es frecuente que la proximidad a los inclividuos o a los sucesos que nos son afines por razón de tiempo, sea un obstáculo para la recta comprensión objetiva, la cual se produce con más eficacia ,cuando adoptamos un punto de vista distante y elevado. Soranoer ha apreciado muy bien esta situación, y en vez de la afinidad cualitativa, propone la afinidad legal. Según él, es la unidad legal o uniformidad la que aclara el enigma de la comprensión. Así como en Kant-

(13) Lebensformen, pág. 410. 


\section{$-85-$}

dice-las leyes de la conciencia que conoce, coinciden con el esquema fundamental de la legalidad natural objetiva, la legalidad en la comprensión del espíritu sería idéntica con la legalidad del espíritu mismo. ( I4)

La comprensión pucde ser de dos clases: actual e histórica. La primera puede comprender objetos materiales en los que se dan valores, cono los económicos; signos o símbolos, cuya significación es espiritual, como el lenguaje; situaciones espirituales, estados de ánimo, relaciones de pensamiento y personalidades, objetivaciones espirituales, como un manuscrito, una obra de arte, una disposición legal.

La comprensión histórica es la más compleja; porque aquí no sólo se trata de comprender el sentido de un objeto, o de una persona, o de una institución, sino además sus conexiones estructurales con la cultura de un tiempo determinado, su relación con un ambiente y su ubicación en el proceso general de la cultura. La enajenación que requiere el historiador es mucho mayor que cualquier otra, pues necesita transportarse a otras épocas, comprender a otros hombres que no son los de su tiempo y establecer relaciones con la mayor objetividad posible. Spranger da idea de este proceso en el deteniclo examen de la comprensión histórica que nos brinda, en sus Formas de Vida, con relación al caso especial de Sócrates. Un investigador que quisiera comprender a Sócrates histórico, tendría que pasar por las siguientes etapas: I) Recolección de datos (lectura de Jenofonte y Platón). 2) El material examinado tiencle a constituir una imagen total en la que se incluyen noticias sobre la vida, doctrina y muerte de Sócrates. 3) Dentro de esta imagen total histórico-concreta, pone líneas que son interiores a la estructura de su espíritu. Conforma el material a través de

(14) Lebensformen, pág. 412. 
una red de categorias comunes al que comprende y al comprendido. Y realiza toda esta labor desde el punto de vista unitario y estable, descle el cual es comprensible para él la multiplicidad de las expresiones de la vida socrática. 4) Por último, hay un momento critico en el cual se corrigen las visiones inapropiadas. El enlace de lo actual con lo presente $y$ lo futuro, constituye el proceso en el cual se mueven las realidades históricas.

La comprensión histórica, tal como la concibe Spranger, no alcanza a tocar, a pesar de la voluntad de objetivación, la absolutez de sus objetos. "Nosotros no llevamos en nosotros mismos jamás la estructura pura y absoluta del espíritu, sino siempre un alma condicionada, personal e históricamente, la que está al mismo tiempo bajo la influencia de objetivaciones históricas-espirituales". (15) Tal conclusión es inevitable, descle que se sostiene que la comprensión tiene que hacerse partiendo del espiritu subjetivo, del individuo histórica y concretamente constituido. Además, la ley misma del objeto lo mantient, en el acto teorético, en inconmovible condición de heterogeneidad. Si queremos captar esa heterogeneidad desde nuestro propio punto de vista subjetivo, o más bien dicho a través de nuestra subjetividad, el conocimiento histórico estará siempre condenado al relativismo, y en el mejor de los casos se creerá con derecho a captiar únicamente la epidermis, lo fenoménico, lo que puede aprehenderse a través de la red categorial. Hace falta, pues, una teoría de la comprensión histórica, y de cualquier otro tipo de comprensión que, poniendo un poco de lado las precauciones criticas, el objetivismo y el psicologismo, afronte el conocimiento del mundo histórico-cultural, sin la debilidad y el recelo implícitos en las doctrinas que hemos examinado,

(15) Lebensformen, pág. 429. 
en las mismas que se encuentra ya en germen, como en Dilthey, y claramente como en Rickert y Spranger, una tenCencia a considerar la comprensión en su significación objetiva y con referencia a los valores. No se puede admitir la situación teórica de media ciencia, que algunos asignan todavía a las ciencias espirituales, mientras las naturales reciben el homenaje correspondiente a su dignidad. $\mathrm{Ni}$ son motivo suficiente para mantener esta situación, las múltiples dificultades con que tropieza la teoría de la comprensión. Estas mismas dificultades, y aun mayores, tienen que vencer las ciencias de la naturaleza: y sin embargo, sus cultivadores mantienen la fe en su método y en su poder de objetividad.

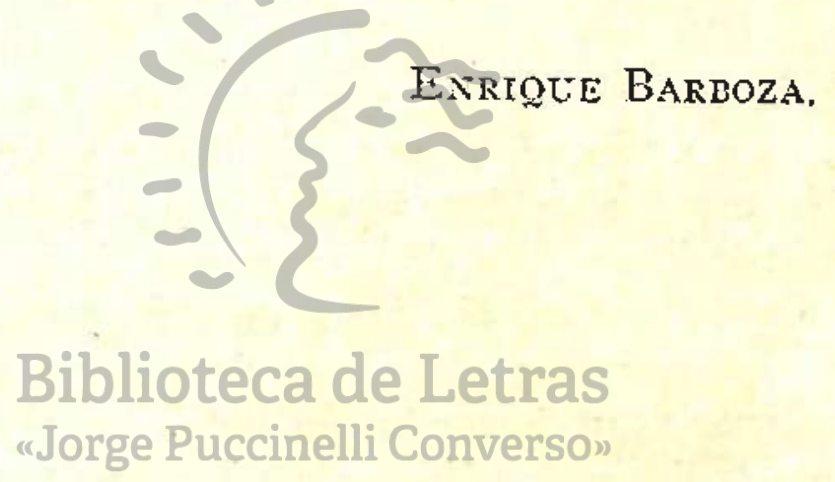

